\title{
O modernismo nas restaurações do SPHAN modernidade, universalidade, brasilidade
}

\author{
Márcia Chuva ${ }^{1}$
}

Resumo

Este artigo analisa o modernismo que se expressa nas restaurações realizadas pelo Serviço do Patrimônio Histórico e Artístico Nacional (SPHAN) e o papel seminal do arquiteto Lucio Costa na definição de procedimentos de restauro e na legitimação das hierarquias estabelecidas entre diferentes instâncias técnicas da instituição. Serão analisados procedimentos que naturalizaram o predomínio do valor estético sobre outras possibilidades de atribuição de valor de patrimônio e de tratamento dos vestígios materiais protegidos. As viagens, constituintes das rotinas dos trabalhos de restauração, produziram um vasto acervo documental, como os relatórios de obras, fotografias e correspondência aqui privilegiados. Ao final, serão apontados possíveis caminhos de interpretação dos efeitos de tais práticas na preservação do patrimônio cultural no Brasil.

\section{Palavras-chave}

Instituto do Patrimônio Histórico e Artístico Nacional, modernismo, universalismo, brasilidade, restauração arquitetônica

Recebido em 1 de junho de 2012

Aprovado em 6 de junho de 2012

CHUVA, Márcia. 0 modernismo nas restaurações do SPHAN: modernidade, universalidade, brasilidade. Revista IEB, São Paulo, n. 55, p. 89-107, 2012.

1 Professora adjunta 2 do Departamento de História da Universidade Federal do Estado do Rio de Janeiro (UFRJ, Rio de Janeiro, RJ, Brasil). E-mail: marciachuva@ gmail.com 


\title{
Modernism in restorations and the SPHAN Modernity, Universality, Brazilianness
}

\author{
Márcia Chuva
}

\begin{abstract}
This article examines the modernism expressed in the restorations carried out by the National Historical and Artistic Heritage Service (Serviço do Patrimônio Histórico e Artístico Nacional - SPHAN), and the seminal role of architect Lucio Costa in defining restoration procedures and establishing hierarchies among different technical departments of the institution. The procedures that naturalized the predominance of aesthetic value over other possibilities for determining equity value and treatment of protected material vestiges will be analyzed. The trips that took place as part of the restoration work produced a vast collection of documents, such as construction reports, photographs, and correspondence, to be showed here. As conclusion, possible ways of interpreting the effects of such cultural heritage preservation practices in Brazil will be presented.
\end{abstract}

Keywords

National Historical and Artistic Heritage Institute, modernism, universalism, Brazilianness, architectural restoration 


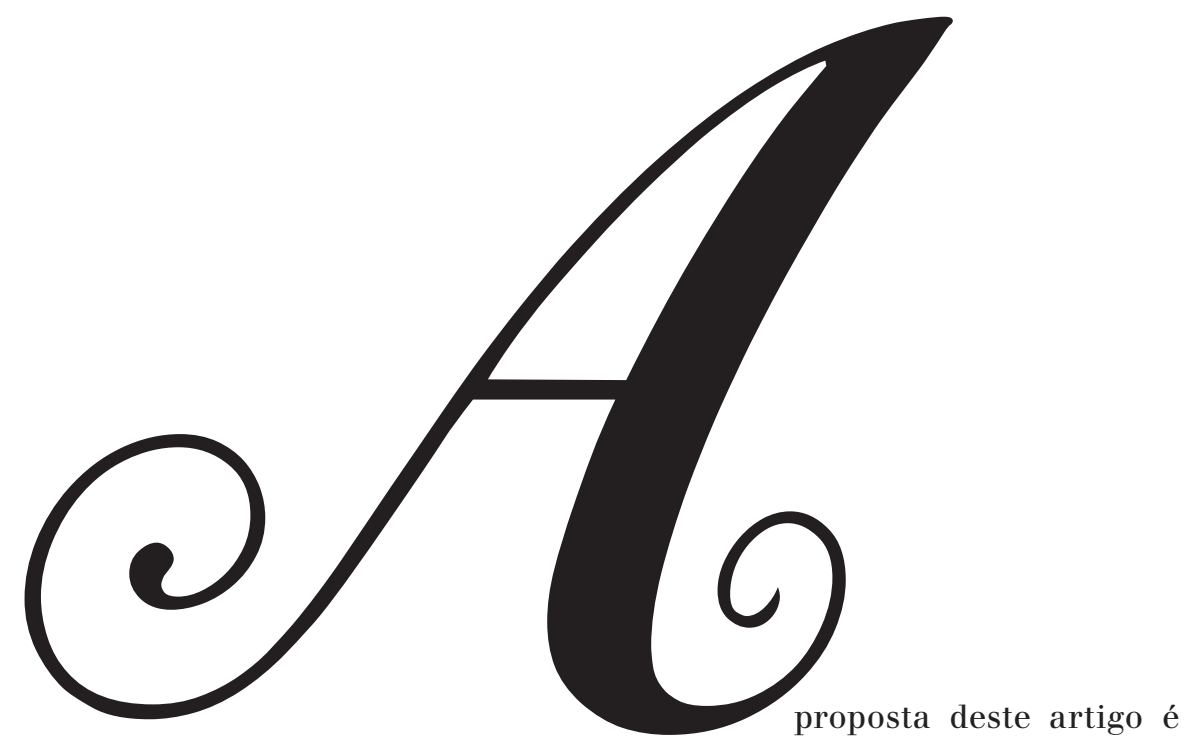

refletir sobre o modernismo que se faz presente na fundação das práticas de preservação do patrimônio cultural no Brasil, especialmente por meio das obras de restauração do antigo Serviço do Patrimônio Histórico e Artístico Nacional (SPHAN). Há algumas singularidades nesse processo, tendo em vista que o mesmo grupo de intelectuais que forjou uma escrita para a história nacional, através da patrimonialização de bens arquitetônicos que foram selecionados como expressão da nacionalidade, também projetou e construiu bens que foram patrimonializados como monumentos nacionais. Essa análise vai focar principalmente a ênfase dada a uma perspectiva estética, que resultou numa intervenção significativa na materialidade do patrimônio arquitetônico tombado, que acaba sendo moldado segundo esse enfoque. Reflete, por fim, sobre o predomínio do valor estético sobre outras possibilidades de atribuição de valor de patrimônio e os seus efeitos na história das práticas de preservação cultural no Brasil.

As relações entre o SPHAN e os intelectuais ligados ao movimento modernista já foram bastante analisadas, tendo nomes expressivos do modernismo ligados visceralmente a essa instituição, que começou a funcionar sob a direção de Rodrigo Melo Franco de Andrade, em caráter experimental, no ano de 1936. Essas relações se deram de inúmeras formas, a começar pelo Anteprojeto elaborado por Mário de Andrade, a pedido do ministro da Educação e Saúde Gustavo Capanema, que havia assumido a pasta em 1934 e promovido uma ampla reforma ministerial, concretizada com a Lei $\mathrm{n}^{0} 387$, de 1937. A partir dessa reforma, o SPHAN passou a funcionar em caráter definitivo e, em novembro de 1937, foi criado o Decreto-lei $n^{0} 25$, que organizou as ações de proteção 
ao patrimônio histórico e artístico nacional, instituindo o tombamento como principal instrumento para essa ação ${ }^{2}$.

Rodrigo Melo Franco de Andrade e Gustavo Capanema, ambos mineiros, vivenciaram a juventude na Rua Bahia, na nova capital Belo Horizonte, nas primeiras décadas do século XX, juntamente com outros intelectuais escritores e políticos, como Afonso Arinos, e também o grande poeta Carlos Drummond de Andrade, um dos nomes mais expressivos do modernismo brasileiro e também Chefe de Gabinete de Capanema e, posteriormente, Chefe do Arquivo do SPHAN. Como aponta Helena Bomeny, "a geração de Drummond poderia transitar pela literatura e pela política, não pela compulsão missionária de Mário de Andrade, mas por uma experiência de oficialidade que se acumulava naquele conjunto de intelectuais, 'a geração dos chefes de gabinete', como gostava de lembrar Cyro dos Anjos"3.

Nas palavras de Rodrigo M. F. de Andrade, seu envolvimento com o movimento modernista se deu em função das fortes relações de amizade mantidas com boa parte do grupo, como Prudente de Moraes Neto, Sérgio Buarque de Holanda e Afonso Arinos de Melo Franco, quando converteu a Revista do Brasil, da qual era editor chefe, num órgão que denominou a quarta corrente do modernismo, pois as outras três eram representadas, uma pelo grupo de Graça Aranha, Ronald de Carvalho, Renato Almeida etc.; outra, a do grupo verde-amarelo - Plínio Salgado, Cassiano Ricardo e Menoti del Picchia -; e outra, um grupo de certa tendência esteticista, representado por Guilherme de Almeida ${ }^{4}$.

O pensamento que se organizou dentro do SPHAN pode ser perfeitamente associado ao segundo tempo modernista, como tratou Eduardo Jardim de Moraes $^{5}$. Para ele, os modernistas começaram a se preocupar, a partir de 1924, com a sua inserção do Brasil na ordem moderna e civilizada mundial a partir da mediação do nacional. Ou seja, sem abrir mão do universalismo, que marca a origem do movimento, passa a buscar os meios de pertencimento à ordem mundial não rompendo com o passado, mas justamente buscando nele as suas singularidades como nação. O processo modernizador (e civilizador) era entendido como um

2 CHUVA, Márcia. Os Arquitetos da memória: sociogênese das práticas de preservação do patrimônio cultural no Brasil. Rio de Janeiro: UFRJ, 2009.

3 BOMENY, Helena Bousquet. Guardiães da Razão. modernistas mineiros. Rio de Janeiro: UFRJ/Tempo Brasileiro, 1994, p. 120-121.

4. ANDRADE, Rodrigo Mello Franco de. Rodrigo e seus tempos: coletânea de textos sobre artes e letras. Rio de Janeiro: MinC/SPHAN/PróMemória, 1986, p. 238.

5 MORAES, Eduardo Jardim de. Modernismo revisitado. Estudos Históricos. Rio de Janeiro, v.1, n.2, 1988. 
deslocamento da parte em direção ao todo - da periferia ao centro. Esse era o caminho a ser trilhado, sem perda ou abandono dos referenciais, ao contrário, valorizando as singularidades da parte em relação ao todo. Segundo Jardim, o modernismo brasileiro passa a se interessar pelos problemas que dizem respeito a sua identidade e à determinação da identidade nacional. Agora, "para o ingresso na modernidade serão discutidas as mediações que irão constituir o seu caminho e sua garantia" ${ }^{6}$.

Para tratarmos do modernismo que se expressa nas restaurações do SPHAN, como é intenção nesse artigo, o foco volta-se para o arquiteto Lucio Costa, que atuou no SPHAN de 1937 até a década de 1970. Como analisou Guilherme Wisnik (2007), Lucio Costa converteu-se ao modernismo e se tornou o principal intelectual a formular um programa conceitual que conectava a arquitetura moderna internacional e a arquitetura tradicional luso-brasileira. Contudo, a documentação para o seu estudo é ainda escassa, embora avanços importantes tenham surgido, recentemente, com a divulgação pela Casa de Lucio Costa, de documentos pessoais do arquiteto, boa parte já disponível eletronicamente. A exposição A arquitetura portuguesa no traço de Lucio Costa: bloquinhos de Portugal é fruto do acesso a essa documentação. Inaugurada em junho de 2012, no Centro Cultural da Caixa, Rio de Janeiro, com a curadoria do arquiteto José Pessôa, essa exposição apresenta os caderninhos de campo em que Lucio Costa fazia suas anotações e desenhos, na viagem a Portugal, realizada entre 1948 e 1952, comparados às fotografias tiradas por Pessôa, dos mesmos locais, em 2011.

Para Wisnik, antes mesmo da sua conversão ao modernismo, Lucio Costa já refletia “um 'espírito geral' capaz de definir constantes para a arquitetura brasileira colonial, cuja força de reiteração deveu-se à existência de uma tradição decantada no saber popular, e não na cultura erudita"7. Para isso, percorreu um caminho próprio, de contato e conhecimento da arquitetura colonial brasileira, especialmente, a partir da sua viagem à cidade de Diamantina.

Veremos então como se concretizou no Brasil esse projeto moderno instaurado na prática de preservação do patrimônio histórico e artístico a partir das restaurações. A “área central” do SPHAN era composta por Rodrigo Melo Franco de Andrade, e a seção Técnica, constituída, nos anos 1930 e 1940, por um grupo de arquitetos modernos formado na Escola de Belas Artes do Rio de Janeiro, capitaneado por Lucio Costa.

6 Idem, p. 229.

7 WISNIK, Guilherme. Plástica e anonimato: modernidade e tradição em Lucio Costa e Mário de Andrade. Novos Estudos, n.79, nov.20o7, p. 171. 
Segundo Ítalo Campofiorito ${ }^{8}$, esses arquitetos não gostavam do adjetivo modernistas, preferem ser chamados de "modernos", tendo em vista não se tratar de um estilo, mas de uma filosofia. São eles: Renato Soeiro, José de Souza Reis, Alcides da Rocha Miranda, Edgard Jacintho, Paulo Thedim Barreto, que ingressaram no SPHAN entre 1937 e 1940. Eles trabalhavam no Rio de Janeiro, coordenando as ações do Serviço em todo o Brasil. Para as representações regionais era preciso recorrer a outros profissionais, pois havia uma escassez de arquitetos formados (ainda então formados nas Belas Artes). Eram em geral engenheiros, como Ayrton de Carvalho, em Pernambuco e também escritores, como o poeta modernista Godofredo Filho, na Bahia.

Na leitura da documentação relativa às obras realizadas nos anos iniciais de funcionamento do SPHAN e de depoimentos de técnicos antigos da instituição, alguns deles publicados na série Memória Oral do IPHAN, "área central" era a denominação informal dada à equipe de profissionais constituída na sede do Serviço, no Rio de Janeiro que, sob a coordenação direta de Rodrigo M. F. de Andrade, dava as orientações técnicas aos trabalhos, tendo um caráter normatizador e controlador das ações empreendidas nas sedes regionais. Havia, nesse período, representações regionais do SPHAN em Pernambuco, Bahia, Minas Gerais, São Paulo e Rio Grande do Sul, que dispunham, em geral, apenas do assistente técnico e um secretário. Algumas regionais contaram, como São Paulo, com auxiliares técnicos, que davam apoio em trabalhos de pesquisa, levantamento, viagens de fiscalização etc.

Essa estrutura, ainda que reduzida, garantia um forte controle das ações implementadas nas sedes regionais do SPHAN, associado a uma forte centralização institucional deu o tom das relações que o grupo central estabeleceu com os técnicos das representações regionais. A força da palavra de Lucio Costa e sua autoridade sobre o grupo é evidente desde os primeiros anos, como se pode ver na documentação levantada e como veremos aqui por meio de sua própria fala.

Nos anos 1930, inexistiam, no Brasil, experiências significativas de restauração, não havendo um conhecimento acumulado, tampouco um lugar apropriado para o seu exercício. Mas a restauração arquitetônica não era propriamente uma novidade para os arquitetos do SPHAN, que já haviam tido contato com as diferentes teorias a respeito e as experiências que se realizavam na Europa, desde o século XIX, não somente em virtude da formação de grande parte deles, na Escola de Belas Artes,

8 CAMPOFIORITO, Ítalo. Introdução: as primeiras árvores. Revista do Patrimônio Histórico e Artístico Nacional, n. 26, 1997. 
do Rio de Janeiro, mas principalmente em função da participação de Lucio Costa em Congressos Internacionais de Arquitetura Moderna (conhecidos pela sigla CIAM), tendo se tornado, segundo ele próprio, o "arquiteto incumbido pelo CIAM de organizar o grupo do Rio"9, depois de ter participado, em 1933, no IV Congresso Internacional de Arquitetura Moderna. O documento produzido nesse encontro deveria ser um dos norteadores das decisões tomadas na ação de restauração do patrimônio arquitetônico no SPHAN. Nele se estabelecia que os valores arquitetônicos deveriam ser salvaguardados e tinha como princípio geral a recusa ao emprego de estilos passados nas novas construções, prática considerada nefasta e intolerável, por se tratar, segundo o documento, de uma cópia servil que condenaria o passado à mentira.

Obviamente que Lucio Costa, presente no CIAM em 1933, conhecia a Carta de Atenas, apelidada de Carta do Restauro, elaborada em 1931 como resultado do Encontro Internacional realizado pelo Escritório Internacional de Museus, da Sociedade das Nações, em outubro de 1931, visando "a salvaguarda das obras primas nas quais a civilização se tenha expressado em seu nível mais alto e que se apresentem ameaçadas"10. Esse documento foi citado por Rodrigo Melo Franco de Andrade como norteador dos trabalhos do SPHAN.

\section{O critério estético}

Dentre as recomendações da Carta de Atenas, havia a indicação da menor intervenção no monumento durante as obras de restauração, a fim de expor sua historicidade. Nesse sentido, tais obras deveriam visar à conservação, bem mais que a restauração. Contudo, o que verificamos na gestão do patrimônio tombado foi a opção pela restauração como um procedimento recorrente e regular, muito mais que pela conservação. Isso se deu de modo recorrente, tornando-se uma rotina nas práticas de restauração dos imóveis tombados, como veremos.

Qual seria a intenção ao se adotarem tais procedimentos, aparentemente contrários às recomendações internacionais que o Brasil era signatário? Na leitura dos relatórios de diferentes obras e também em alguns artigos dos arquitetos do SPHAN publicados na revista do órgão,

9 Carta de Lucio Costa para Rodrigo Melo Franco de Andrade, reproduzida em MOTTA, Lia. O SPHAN em Ouro Preto: uma história de conceitos e critérios. Revista do Patrimônio Histórico e Artístico Nacional, n. 22, 1987, p. 109.

10 IPHAN. Cartas Patrimoniais. 3. ed. Rev. Aum. Rio de Janeiro: IPHAN, 2oo4, p. 16. 
pode-se notar a necessidade de desvendar as origens da nação - para conhecê-las e cultivá-las - na sua expressão arquitetônica, que se encontrava encoberta por reformas inadequadas. Ou seja, buscavam os traços definidores das origens da nação, que se escondiam por trás das inúmeras reformas sofridas pelo patrimônio edificado. Na busca do "aspecto primitivo", "original", pretendia encontrar a "harmonia de estilo" rompida com reformas posteriores.

Para recuperar à nação a posse das suas origens, o patrimônio deveria manter-se e/ou voltar ao seu estado primitivo. A restauração do patrimônio tombado buscou recuperar, física e simbolicamente, as origens da nação, promovendo a reconstituição de um patrimônio “original", "autêntico" e "primitivo", "genuíno", vocabulário esse que pode ser verificado na documentação trabalhada na série Obras. Os vínculos com o passado e o tradicional eram necessários para mediar o ingresso do Brasil no mundo civilizado, dentro dos princípios do modernismo com os quais esse grupo se identificava.

A nação, nessa perspectiva, tem uma origem, que pode ser compreendida como o momento em que foi dado o salto em direção ao novo, como algo que se liberta e rompe com a continuidade, em relação à produção arquitetônica e artística portuguesa. Esse profundo processo de renovação foi identificado por boa parte desses intelectuais envolvidos com o SPHAN, na produção artística mineira do século XVIII mineiro, momento em que se apresentam as origens de uma produção artística autenticamente brasileira. Essa ideia vinha sendo compartilhada desde os anos 1920, quando o período colonial e o popular ganharam estatuto de brasilidade. Ainda que Mário de Andrade não tenha tido papel significativo com esses arquitetos que dirigiam as restaurações do SPHAN, tendo se isolado nos anos 1940 na Sede regional do SPHAN em São Paulo até sua morte em 1945, vale destacar que também ele considerava a arte colonial dotada de limpeza e economia formal, vendo muito de moderno nas suas expressões mais populares.

Os intelectuais do SPHAN seguem esse pensamento, que se torna dominante nos anos 1930, dando a ele uma configuração estética, ao se tratar das estratégias de restauração.

Isso fica muito claro em vários artigos de Lucio Costa, que atribuiu esse salto qualitativo àqueles que denominou "renovadores" do século XVIII. Bom exemplo é seu artigo sobre arquitetura jesuítica no Brasil, publicado no n. 5 da Revista do Patrimônio, no qual afirma:

Se algumas vezes os monumentos barrocos merecem realmente essa pecha de anomalias artísticas, a grande maioria deles 
- inclusive daqueles em que o arrojo da concepção ou o delírio ornamental atingem seu clímax - é constituída por autênticas obras de arte, que não resultaram de nenhum processo de degenerescência, mas, pelo contrário, de um processo legítimo de renovação. ${ }^{11}$

No sistema classificatório da arquitetura tradicional brasileira, que Lucio Costa apresenta nesse mesmo artigo, as transformações na arquitetura religiosa e civil, nos "dois primeiros séculos" (séculos XVI e XVII), caminhavam em direção ao barroco - considerado expressão artística maior do período colonial - ponto de chegada e de partida posterior, momento de profunda renovação, que deu origem a um novo tempo. O tempo da brasilidade, de fundação da nação brasileira, é o tempo da arte barroca no Brasil.

Restaurar era forjar a materialidade do patrimônio. Os arquitetos modernistas do SPHAN construíram uma versão da história da nação, representada como testemunho material de um tempo originário e heróico.

\section{As viagens e as redes}

Segundo Guilherme Wisnik ${ }^{12}$, Lucio Costa e Mário de Andrade tiveram em comum a relação com certas viagens que serviram para lhes apresentar novas realidades, especialmente aquelas realizadas a Minas Gerais, ainda nos anos 1920.

Nas práticas de preservação do patrimônio no Brasil, as viagens continuaram cumprindo um papel seminal, quer para as descobertas de novas realidades, que continuam ocorrendo, quer em função das necessidades de fiscalização, conservação e restauração dos bens tombados. As viagens são constituintes dessas rotinas de trabalho que se configuram e são naturalizadas nesse momento de invenção de procedimentos, e passam a fazer parte do mundo do trabalho com o patrimônio. $\mathrm{O}$ que fundamenta a necessidade incontornável de contato, de experiência e de vivência com o bem a ser protegido ou restaurado? Para a fruição estética, essa experiência é imprescindível.

11 COSTA, Lucio. Arquitetura dos jesuítas no Brasil. Revista do Património Histórico e Artístico Nacional, n. 5, 1941, p. 11.

12 WISNIK, Guilherme. op. cit. 
Os técnicos do SPHAN instalados nas regiões também faziam constantemente viagens para toda a região sob sua responsabilidade, para a fiscalização e para o acompanhamento das obras. Do mesmo modo, as viagens eram parte da rotina de trabalho dos arquitetos do Rio de Janeiro, pois as "descobertas" das características originais do monumento eram feitas in loco. Contudo, podemos imaginar que os deslocamentos, nos anos 1930 e 1940, eram bastante precários, bem como os serviços de hotelaria.

A cidade de Ouro Preto não é exatamente um bom exemplo de escassez de serviços, pois eram incomparavelmente superiores aos das inúmeras localidades esquecidas pelo interior, as quais passaram a receber a visita do SPHAN. A “excepcionalidade" com que foi tratada a cidade de Ouro Preto é anterior ao próprio SPHAN e estava relacionada ao seu reconhecimento prévio como cidade Monumento Nacional, em 1933, aos trabalhos da Inspetoria de Monumentos Nacionais, que fez, a partir de 1934, várias restaurações na cidade, assim como aos investimentos do governo estadual, desde os anos 1920. Nesse contexto, uma interessante correspondência, datada de1938, trocada entreo dono dofamoso hotel, bare restaurante Toffolo, de Ouro Preto - até poucos anos atrás ainda existente-, Olívio Toffolo, o engenheiro Epaminondas de Macedo, que havia trabalhado na IMN e se manteve ligado ao SPHAN, e também Rodrigo M. F. de Andrade ${ }^{13}$, dava conta do andamento das obras na cidade e evidenciava o apoio que prestava, dando infraestrutura para os técnicos do SPHAN e compartilhando, assim, das redes tecidas em prol da proteção ao patrimônio histórico e artístico nacional.

Por outro lado, deslocando-se mais para o interior - em Goiás, por exemplo-, as condições materiais eram bem mais precárias. O arquiteto Edgard Jacintho, após viagem à cidade de Pirenópolis, em Goiás, feita em função da solicitação do prefeito local para avaliar as possibilidades do SPHAN restaurar a Igreja Matriz de N. S. do Rosário, único bem tombado no estado de Goiás e em todo o centro-oeste no período, elaborou um interessante e detalhado relatório a respeito das condições de execução de uma obra numa região tão distante e das dificuldades em se constituir uma equipe para executá-la. A visita foi feita sob os auspícios do Arcebispo de Goiás, que por intermédio de Jacintho fez uma doação para o Museu do Ouro. Na documentação pesquisada, encontramos uma carta de agradecimento de Rodrigo M. F. de Andrade ao Arcebispo e, também,

13 Essa correspondência pode ser localizada na Série Obras do Arquivo Central do IPHAN, na caixa relativa à Igreja Matriz do Pilar, Ouro Preto/MG (Caixa 263/ pasta 1114 , parte 3). 
uma ordem de pagamento em nome de Dimitri Rechtnikow, construtor indicado pelo Arcebispo, tendo em vista o fato de ser homem da cidade, para realizar a empreitada das obras da Matriz.

Como se vê, as redes de relações vão sendo tecidas, enraizando-se no território nacional, ao passo que as viagens e as restaurações vão sendo executadas.

Apesar de todos os percalços, a observação visual do próprio monumento era um método de trabalho recorrente, sendo o próprio monumento a principal fonte de informação utilizada para percepção das características originais que buscavam nos imóveis: isto é, tentava-se identificar o quê os vestígios, enquanto documento, ainda guardavam sobre suas próprias origens. Na análise física do monumento, descobriam-se os materiais utilizados, as reformas que já havia sofrido etc. Juntamente com material iconográfico e monografias históricas de produção local, que foram fontes privilegiadas nessas buscas, recorria-se também à memória da população local, entrevistando moradores e o "testemunho de pessoas idosas", como afirmou Godofredo Filho em relação às obras do Convento do Carmo, em Cachoeira, no seu parecer ${ }^{14}$.

\section{Técnicas e tecnologia}

A fotografia, por sua vez, era fonte produzida para as tomadas de decisão a respeito dos rumos da restauração. Nas restaurações, elas não eram simplesmente um registro da memória da restauração, mas seu principal instrumento de análise, especialmente porque os arquitetos do Rio de Janeiro precisavam acompanhar e, ao final, avalizar a restauração realizada. Por meio das fotos enviadas pelas sedes regionais, os arquitetos pretendiam ver e demonstrar os elementos arquitetônicos do prédio e deduzir suas características originais, sua representatividade dentro de uma série e, ainda, suas relações de "parentesco" com outros imóveis. Como um objeto cultural por excelência, a fotografia não se interpõe entre o texto escrito (pareceres, relatórios etc.) e seu leitor para complementar seu entendimento. Ela não era um apoio ilustrativo do texto. Na verdade, ela, a um só tempo, autenticava a "realidade" narrada e constituía uma nova materialidade, independente, embora ali estivesse presente para retratar os monumentos. As obras foram fartamente fotografadas em todo o processo. Vários fotógrafos prestaram serviços para o

14. Parecer de Godofredo Filho, 2 maio 1939. Série Obras, Arquivo Central, IPHAN, caixa 8 /pasta 36 . 
SPHAN, tratando-se, naquela época, de trabalho profissional, que exigia conhecimento técnico e uso de equipamentos. Os fotógrafos eram contratados para executar um trabalho técnico, acompanhando as demandas dos arquitetos que, em geral, os acompanhavam nas viagens. Portanto, fotógrafos como Gautherot, ao prestarem serviços para o SPHAN, eram orientados a evitar fotos artísticas, subjetivas. Esperava-se que a fotografia cumprisse um papel de prova e de verificação da realidade, para aqueles impossibilitados de vivenciar essa experiência in loco ${ }^{15}$.

As restaurações empreendidas pelo SPHAN serviram também como catalisadoras de grupos regionais dispersos e de diferentes estratos sociais. Isso se processou na medida em que trabalhadores e artesãos locais, detentores de um saber sobre o manuseio de materiais antigos e em desuso e de técnicas de construção antigas, muitas delas semiartesanais, entravam nesse circuito prestando serviços diretamente ligados às obras de restauração em troca de remunerações periódicas (tais como pedreiros, carpinteiros, marceneiros, mestres de obra, serralheiros, oleiros etc.). Dentro dos princípios modernos, era preciso adotar as técnicas e tecnologias disponíveis na época em que foi construído o imóvel, pois elas estabelecem a harmonia de estilo.

Esses profissionais foram sendo "descobertos" com o desenrolar dos trabalhos de conservação e restauração do SPHAN, nas localidades do interior, e incorporados aos empreendimentos em função de suas especialidades e do domínio das técnicas construtivas tradicionais. Contudo, era bastante difícil cumprir à risca o planejado, em função dos percalços para sua execução a bom termo.

Como em várias outras situações, esses aspectos foram identificados nas obras de restauração empreendidas na Casa na rua do Amparo, n. 28, em Olinda. Em 1940, Ayrton Carvalho mantinha a Direção do SPHAN atualizada, informando sobre as descobertas feitas a respeito do processo de construção antigo e do material empregado. Descrevia com detalhes, numa estreita correspondência, as técnicas e os procedimentos adotados, e, passo a passo, o patrimônio era construído. Exemplo interessante, nesse caso, foi o desenrolar da solução dada ao piso do imóvel. Acordaram que a melhor ideia era colocar "ladrilho de barro cozido, com as mesmas dimensões dos primitivos ainda existentes" ${ }^{\prime \prime}$. Em seguida, Carvalho informava sobre as dificuldades em conseguir os ladrilhos de

15 CUNHA, Oscar Henrique Liberal de Brito; LIMA, Francisca Helena Barbosa e MELHEM, Mônica. Afotografia na preservação do patrimônio cultural: uma abordagem preliminar. Rio de Janeiro: IPHAN, 2008.

I6 Parecer de José de Souza Reis, 1941. Série Obras, Arquivo Central, IPHAN, caixa 343 . 
barro, já que a encomenda feita em uma usina no interior havia chegado toda estragada. Outra solução deveria ser adotada.

Mais uma vez, em outra correspondência com Rodrigo Melo Franco de Andrade, Ayrton Carvalho informava sobre as dificuldades em se conseguir material adequado, que costumava procurar, inclusive, em obras de demolições. Comunicou que, para substituir a antiga madeira amarela de que eram feitas as ripas do telhado, decidiu utilizar o cedro, material semelhante ao primitivo, por não ter encontrado as ripas de emberiba nas dimensões que já se encontram em desuso. Mesmo assim, informava que havia empregado materiais semelhantes aos primitivos ${ }^{17}$.

Para todos esses serviços de fabricação de materiais novos semelhantes aos "primitivos", era necessário utilizar mão de obra local que dominasse as técnicas antigas, conforme o trabalho realizado nas ferragens. Carvalho informava terem sido refeitas ferragens "análogas às antigas", assim como "o fogão de barro [que] foi inteiramente refeito"18. Como se pode ver, não se detinham apenas aos elementos da arquitetura. Apenas para essa obra de restauração, de pequeno porte diante das grandes obras então realizadas pelo SPHAN, foram contratados serviços locais de carpinteiros, serralheiros, oleiros, além de mestres de obra, pedreiros etc., identificados na região.

Para os problemas surgidos na execução das restaurações, a busca do domínio de técnicas construtivas antigas, muitas vezes com materiais que não eram mais produzidos, aliou-se às novas soluções advindas da revolução industrial, que teve no concreto armado - marco tecnológico da arquitetura moderna - seu grande salto qualitativo em termos construtivos. Esse critério adequava-se às determinações da Carta de Atenas, no que se referia aos materiais de restauração, pois aprovava o emprego adequado de todos os recursos da técnica moderna e especialmente o concreto armado ${ }^{19}$.

Os saberes tradicionais, encontrados localmente, eram valorizados. E a relação entre esses saberes - relativos ao domínio das técnicas construtivas tradicionais e da tecnologia avançada do concreto armado - se dava numa só direção: que aponta para a civilização, sob a orientação daqueles que poderiam introduzir o conhecimento moderno e as novas tecnologias, para a realização desse projeto de modernidade que se expressava via restaurações.

17 Carta de Ayrton Carvalho a Rodrigo Melo Franco de Andrade, de 14 out. 1941. Série Obras, Arquivo Central, IPHAN, caixa 343.

18 Idem, ibidem.

19 IPHAN. Cartas Patrimoniais. op. cit., p. 15. 
As representações regionais do SPHAN estavam submetidas ao controle do Rio de Janeiro, que instituía as rotinas e os procedimentos. Para esse controle, eram apresentados regularmente à Direção os trabalhos concluídos através de fotos e relatórios, que se colocavam à prova para avaliação,

José de S. Reis, arquiteto da "área central" do SPHAN, avalizou o resultado alcançado, destacando que, com base na comparação das fotografias tiradas ao longo do processo de restauração, a restituição da fachada à sua feição arquitetônica original foi executada de maneira plenamente satisfatória, ao comparar as fotos tiradas ao longo do trabalho ${ }^{20}$.

Em seus pareceres, Lucio Costa não abria mão de suas convicções modernas, que se tornaram uma constante, como um ideário no qual todos se formaram. Sobre a consulta feita ao SPHAN a respeito da construção de um edifício dos Correios e Telégrafos, na Praça da Igreja Matriz de São Pedro, em Rio Grande, no Rio Grande do Sul, Lucio Costa afirmava não haver incongruência entre progresso e preservação do patrimônio e dava uma aula de princípios modernos de urbanismo, em defesa da manutenção da praça livre de construções, para que a Matriz pudesse ali reinar como historicamente havia sido:

Aliás, a técnica do moderno urbanismo visa ampliar e não restringir as áreas livres arborizadas a fim de lhe amenizar a vida urbana. (...) a construção projetada, pelas suas proporções e má qualidade arquitetônica, compromete a escala e a harmonia do logradouro em detrimento da monumentalidade da Matriz. (...) o recurso à arborização da mesma espécie dos magníficos exemplares ainda existentes, poderá, dentro de algum tempo, esconder as deficiências arquitetónicas da edificação nova, restituindo-se assim ao velho terreiro, (...) a atmosfera perdida, simples e digna.

Finalmente, na minha qualidade de arquiteto responsável, não posso deixar de lamentar que, precisamente quando a arquitetura brasileira contemporânea vem sendo louvada no mundo inteiro, repartições federais ainda contribuam para a depravação do gosto das populações da província, e o conseqüente aviltamento das nossas cidades, com obras pseudo modernas desse teor, em vez de propiciarem, na instalação de seus serviços, a construção de

20 Parecer de José de Souza Reis, 16 set. 1943. Série Obras, Arquivo Central, IPHAN, caixa $2 /$ pasta 14. 
prédios verdadeiramente modernos onde a eficiência funcional e a beleza plástica se confundam. ${ }^{21}$

Foram princípios estéticos - apoiados numa ideia de beleza arquitetônica determinada pela "harmonia de estilo" e pela funcionalidade da arquitetura - que determinaram a construção do patrimônio histórico $e$ artístico nacional, princípios esses definidos pelos arquitetos do SPHAN, ligados ao modernismo, dando uma direção, que determinava os bens a serem selecionados para tombamento e as formas a serem assumidas quando restaurados.

O choque de temporalidades no qual todo drama da modernidade é vivenciado, enfrentou no Brasil, não a ruptura, mas a associação entre tradição e modernização, e teve no âmbito das restaurações do SPHAN uma de suas mais profícuas expressões e realizações, na medida em que confirmavam a crença de que o sonho modernista - de demarcação de uma nova temporalidade para a nação brasileira sem perder as suas particularidades, a "brasilidade" -, enfim se concretizava.

\section{A arquitetura moderna como patrimônio}

O movimento modernista tem lugar justamente no momento em que se instala um sentimento de pertencimento a um novo tempo, um desejo de civilizar-se, com direção, sentido. O progresso faz parte desse projeto universal, que pretende construir a cidade moderna para todos. A vila operária da Gamboa, projetada por Lucio Costa e Gregori Warchavchik, de 1931, e o Conjunto do Pedregulho, projetado por Affonso Eduardo Heidy, de 1952, são exemplos significativos, na cidade do Rio de Janeiro, do sonho moderno de cidade.

Mas refletindo acerca da segunda fase do modernismo, como tratou Eduardo Jardim de Moraes, na qual vislumbramos o modernismo que se enraíza no $\mathrm{SPHAN}^{22}$, esse sentimento de pertencimento a um novo tempo estabelece uma relação com o passado, de distanciamento e reaproximação, demarcando dois momentos precisos - o originário, que constitui a ancestralidade da nação - sua origem, e o momento presente, de refundação, que é capaz de reconquistar o elo perdido constituinte do ser nacional, qual seja, o "espírito de invenção", a "seiva criadora",

21 Parecer de Lucio Costa, 17 dez. 1947. Processo de tombamento n. 1-T, Arquivo Central do IPHAN.

22 MORAES, Eduardo Jardim de. op. cit. 
o "sentido plástico real" e a "espontaneidade". Lucio Costa carregava a crença de que a produção moderna da arquitetura resgataria essa que ele chamou de "a boa tradição"

Nessalinha depensamento, os arquitetos modernistas consagraram a própria arquitetura que produziam como aquela que efetivamente representaria a nação moderna. Construíram assim, simbólica e materialmente, o patrimônio histórico e artístico nacional mediante a eleição da arquitetura barroca colonial e a sua restauração. E, na repetição, consagraram-se na ordem inversa, construindo materialmente a arquitetura moderna e elegendo-a simbolicamente como patrimônio histórico e artístico nacional. Como é sabido, o tombamento de certa arquitetura moderna deu-se concomitantemente à sua produção, pelos seus próprios produtores. Essa arquitetura tornou-se hegemônica no campo arquitetônico brasileiro, mas não era a única produção moderna existente naquele momento. Não se pretende desenvolver aqui as disputas que deixaram na invisibilidade, por longos anos, a arquitetura moderna que se produziu em São Paulo e Minas Gerais, por exemplo, mas a que se refletir sobre essa imposição de visibilidade e invisibilidade que a patrimonialização dessa arquitetura moderna promoveu, com a força da ação desse grupo no sentido da sua própria consagração, como veremos a seguir.

Em 1947, a Igreja de São Francisco de Assis, na Pampulha, em Belo Horizonte, projetada por Oscar Niemeyer, foi tombada pelo SPHAN, com processo de tombamento aberto no mesmo ano, com parecer de Lucio Costa. A Igreja, recém-construída, encontrava-se com problemas estruturais desde a sua construção e precisava ser restaurada, antes que ruísse. Por sua vez, a Igreja ainda não havia consagrado o novo templo, em função do estranhamento causado pela forma adotada. Lucio Costa, em seu parecer a favor do tombamento da igreja, afirma que "o valor excepcional desse monumento o destina a ser inscrito, mais cedo ou mais tarde, nos Livros de Tombo, como monumento nacional"24.

Em 1948, foi a vez do Palácio Gustavo Capanema, sede do Ministério da Educação e Saúde, no Rio de Janeiro, cujo processo foi aberto em 1944, antes mesmo da sua inauguração oficial. Lucio Costa não foi à inauguração do prédio, mas escrevendo para Capanema, afirmava tratar-se “de uma obra de arquitetura destinada a figurar, daqui por

23 COSTA, Lucio. Documentação necessária. Revista do Patrimônio Histórico e Artístico Nacional, n. 1, 1937.

24. Parecer de Lucio Costa, 8 out. 1947. Processo de tombamento 373-T-47, Arquivo Central, IPHAN. 
diante, na história geral das belas artes como o marco definitivo de um novo e fecundo ciclo da arte imemorial de construir" ${ }^{25}$.

Como se depreende das palavras de Lucio Costa, para esse grupo de intelectuais do SPHAN, as origens de uma produção autenticamente nacional estavam no seio de um movimento artístico considerado profundamente renovador, que desde a "pureza" e "verdade" das construções gregas jamais havia se repetido e que, a partir do barroco, só teve novo momento renovador com a arquitetura moderna, advinda da revolução industrial. Foi esta que possibilitou a invenção de novos materiais, novas formas e técnicas. Construía-se, assim, a genealogia da "boa arquitetura”, universal, em que a produção brasileira se enquadrava.

\section{A "boa arquitetura" - moderna, nacional e universal}

Dentre os atributos que caracterizariam a "boa arquitetura" destacam-se: a funcionalidade, as estruturas aparentes, sem disfarces, a utilização das técnicas contemporâneas ao seu próprio momento e a harmonia de estilo própria à "razão arquitetônica" do prédio, cujas reformas sofridas seriam uma pretensa reprodução de estilos que lhe eram estranhos. Eram eles norteadores das restaurações.

O segundo momento de produção da "boa arquitetura" no Brasil se deu, para esses arquitetos, com a produção modernista, considerada autenticamente nacional e fundadora de uma nova temporalidade. Dessa forma, são os mesmos princípios norteadores da arquitetura moderna que identificavam uma genealogia da "boa arquitetura": ela seria, então, a herdeira da "boa tradição".

Essa é a estética modernista que fez carreira no SPHAN. Ela definia então a "boa arquitetura" e as características do patrimônio histórico e artístico nacional a serem restauradas por meio de códigos cujos sentidos eram compartilhados por aqueles que se formaram nessa experiência, tais como: beleza, autenticidade, harmonia, simplicidade, singeleza, graça, sobriedade. Não pretendiam destacar características de um "estilo barroco", mas sim da "boa arquitetura": mais uma vez, verifica-se o compromisso modernista com a universalidade.

Para discriminar as características adquiridas pelos imóveis ao longo do tempo, e que haviam amesquinhado a "boa arquitetura", outros adjetivos eram também utilizados, codificando valores. Dentro desses

25 Apud SCHWARTZMan, Simon et. al. Tempos de Capanema. Rio de Janeiro: Paz e Terra; São Paulo: Edusp, 1984, p. 356 . 
códigos, os adjetivos que desqualificavam o patrimônio, em função de reformas que havia sofrido, ou atribuídos à "má" intervenção na vizinhança do bem tombado, justificando a necessidade de restauração do monumento tinham por base a perspectiva estética da fidelidade às origens: "indigno restauro"; "restaurações desfiguradoras e desastradas", "perdendo as características primitivas"; "composição pouco feliz"; "valor medíocre"; "sacrificando, atravancando o bem tombado"; "inexpressividade"; "prejuízo da expressão arquitetônica” (do bem tombado).

\section{Efeitos da prevalência do valor estético na atualidade}

A “má arquitetura”, parodiando Lucio Costa, não é somente aquela que transformou o monumento com reformas espúrias ou indignas. Há monumentos, seguindo a estética modernista, que são construídos em bases falsas porque não correspondem às técnicas e tecnologias do seu próprio tempo, da sua contemporaneidade e, portanto, expressam a má arquitetura, que deve ser combatida. O caso do Palácio Monroe, antiga sede do Senado federal, demolida com a anuência do IPHAN em 1975, é um ótimo exemplo da má arquitetura, na concepção de Lucio Costa e de boa parte dos modernistas que se filiavam ao pensamento daqueles fundadores das práticas de preservação no Brasil. Nos anos 1930, Lucio Costa posicionava-se contra o ecletismo, maior responsável, segundo ele, pela perda de referência na produção nacional e pela importação de valores estrangeiros para a arquitetura brasileira. Responsável também pelo modismo que promoveu uma série de reformas "indignas", causando estragos na harmonia de estilo que reinava no modo de fazer arquitetura tradicionalmente no Brasil. Na verdade, segundo Guilherme Wisnik, suas famosas críticas ao ecletismo foram publicadas em artigos anteriores à sua conversão ao modernismo, datando ainda dos anos 1920, quando esteve ligado aos neocolonais ${ }^{26}$. Nesse momento, já era possível perceber seu esforço em estabelecer uma correspondência funcional entre o estilo (as formas construídas) e o meio físico social, onde as características singulares poderiam aparecer. Para ele, essa correspondência funcional é uma característica da "boa arquitetura" de qualquer tempo, perceptível na arquitetura vernacular colonial no Brasil e na arquitetura moderna brasileira, mas perdida na arquitetura produzida no Brasil em estilo eclético.

26 WISNIK, Guilherme. op. cit. 
Desse modo, em 1972, trinta anos após a consagração da sua arquitetura moderna com a inauguração do Ministério da Educação e Saúde, Lucio Costa continuava a renegar esteticamente o ecletismo, posicionando-se contra o tombamento do Palácio Monroe, afirmando que "Pereira Passos, com sua desenvoltura demolidora teria sido o primeiro a tirar dali o aviltado Pavilhão Monroe, cuja presença estorvante não se justifica" ${ }^{27}$.

O Monroe foi demolido e - malgrado todo o aspecto político da sua demolição - imperou, mais uma vez, o argumento estético baseado num ideal de modernidade urbana que há muito estava vencido e, com ele, a negação de uma perspectiva historicista da arquitetura. Para Lucio Costa, a arquitetura - como a obra de arte - não muda de valor com o tempo, com a história.

Em 2006, enfim, o Instituto Estadual de Patrimônio Cultural do Rio de Janeiro (Inepac) tombou os sete remanescentes da primeira geração de edifícios da Avenida Central (atual Avenida Rio Branco, no centro do Rio de Janeiro), que têm características ecléticas, tendo em vista que se tratava da arquitetura de maior sucesso e signo da modernidade, no início do século $\mathrm{XX}$, nas comemorações dos cem anos da abertura da Avenida, nos primórdios da República.

Esse tombamento foi brilhantemente defendido pelo arquiteto Augusto Carlos da Silva Telles - funcionário de carreira do IPHAN -, com base na sua importância para a história da cidade e da nação, como traços do passado no presente.

Se refletirmos sobre todas as transformações ocorridas a partir dos anos 1970 e 1980, especialmente em termos tecnológicos, veremos com certa melancolia a quixotesca posição de Lucio Costa em sua teimosa posição ainda remetida a um projeto de modernidade que se esfacelava no ar. Os deslocamentos da parte em direção ao centro, com vistas ao alcance do universal, parece ter perdido o sentido num mundo em rede e cada vez mais virtual.

Data também de 1972 a Convenção do Patrimônio Mundial Cultural e Natural da Unesco, que institucionalizou o caminho de acesso ao universal. Isso ocorre, curiosamente, no mesmo momento em que as portas do universal foram abertas pelo mundo virtual e, portanto, novas estratégias deconstrução de poder ehierarquias começavam a ser traçadas - momento, talvez, em que o sonho moderno, definitivamente, acabou.

27 PESSÔA, José. Lucio Costa: documentos de trabalho. Rio de Janeiro: IPHAN, 1999, p. 274 . 
